
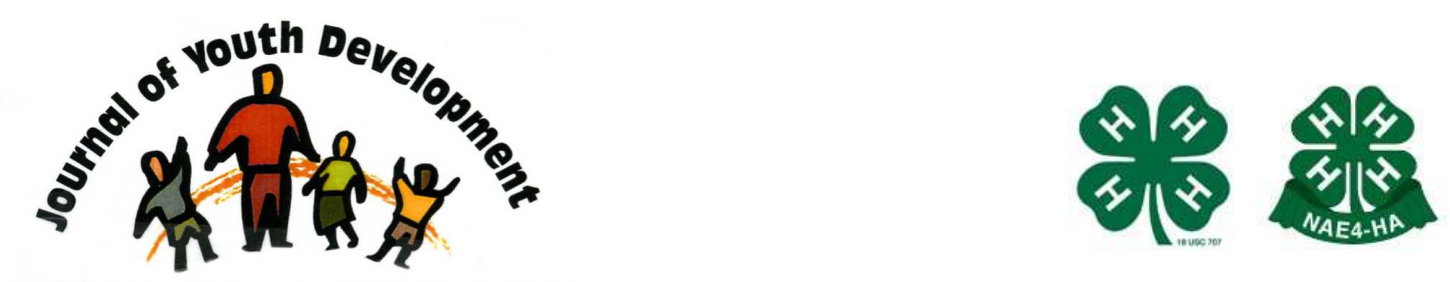

Bridging Research \& Practice

\title{
Aggressors, Victims and Bystanders: Preventing Bullying in the Middle School Environment
}

\author{
Rosemary V. Barnett
}

Family, Youth and Community Sciences

University of Florida

Gainesville, FL

rbarnet@ufl.edu

M.A. Brennan

Agricultural and Extension Education

The Pennsylvania State University

University Park, PA

mab187@psu.edu 


\title{
JOURNAL OF YOUTH DEVELOPMENT \\ bridging research and practice

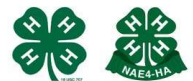

Volume 4, Number 2, Summer 2009

Article 090402FA003

\section{Aggressors, Victims and Bystanders: Preventing Bullying in the Middle School Environment}

\author{
Rosemary V. Barnett \\ University of Florida \\ M.A. Brennan \\ The Pennsylvania State University
}

\begin{abstract}
The research presented in this article examines the effects of implementing a prevention program for bullying and aggressive behaviors to sixth graders in 14 Florida middle schools. The evaluation was conducted as a control/experimental design. The primary goals of this manuscript are to determine: (a) the change from baseline student habits of thought related to violence prevention, (b) student habits of thought related to attitudes and physical behaviors related to violence, and (c) teacher perceptions of student attitudes and behaviors related to violence.

Equally important, this study adds to our understanding of bullying prevention programs by examining the impact of an Aggressors,' Victims' and Bystanders' program in terms of three dimensions: (1) teacher perceptions of student thoughts and behaviors related to their ability to solve conflict, (2) middle school student habits of thought about violence prevention, and (3) middle school student attitudes about behaviors associated with the prevention of violence, including aggressor behaviors and actions and bystander behaviors and actions.
\end{abstract}

\section{Introduction}

It is vital that teachers, administrators, and program/policy developers understand the significant impact that bullying has on both those being bullied, and those doing the bullying. The effects of bullying are harmful to students and have a negative impact on academic achievement and motivation. Youth who are bullied are five times more likely to be depressed than other youth, and also far more likely to be suicidal (Fox, Elliot, Kerlikowske, Newman, \& 
Christeson, 2003, p.4). Equally important, it has been found that students who bully are more likely to skip school, drop out of school, and take part in problematic behaviors such as smoking, drinking alcohol and getting into fights than those who don't bully (Nansel, Overpeck, Haynie, Ruan, \& Scheidt, 2003; Olweus, 1993). Consequently, educators are constantly exploring alternatives for ways to keep students safe and prevent bullying from occurring. It is therefore essential that school administrators, educators and school violence researchers strive to engage middle and high school students in effective school safety and violence prevention programs as a means of offsetting current risk and preventing future risk.

The research presented in this article examines the effects of implementing a prevention program for bullying and aggressive behaviors for sixth graders in 14 Florida middle schools. The evaluation was conducted as a control/experimental design. The primary goals of this manuscript are to determine:

a. the change from baseline student habits of thought related to violence prevention;

b. student habits of thought related to attitudes and physical behaviors which are related to violence; and

c. teacher perceptions of student attitudes and behaviors related to violence.

Equally important, this study adds to our understanding of bullying prevention programs by examining the impact of an Aggressor's, Victim's and Bystander's program in terms of three dimensions:

1. teacher perceptions of student thoughts and behaviors related to their ability to solve conflict;

2. middle school student habits of thought about violence prevention; and

3. middle school student attitudes about behaviors associated with the prevention of violence, including aggressor behaviors, actions and bystander behaviors, and actions.

\section{Review of Literature}

Bullying is a detrimental problematic behavior, especially when it occurs within the school environment. In terms of scope, about $30 \%$ of US teens (over 5.7 million) are involved in bullying, either as a bully, a bullying target, or both (National Youth Violence Prevention Resource Center, 2006). More specifically, in a 2001 national survey of sixth to tenth grade students, $13 \%$ reported bullying others, $11 \%$ reported being the target of bullies, and $6 \%$ reported that they bullied others and were bullied themselves (Nansel, Overpeck, Pilla, Ruan, Simons-Morton, \& Scheidt, 2001). Over $88 \%$ of middle and high school students have reported that they have witnessed bullying in their schools (Hoover, Oliver, \& Hazler, 1992).

While more limited in the past, the definition of bullying has been expanded to include a variety of behaviors. All of these behaviors, however, have the same basic ingredient of a person or a group that repeatedly tries to harm someone who is more vulnerable or weaker (National Youth Violence Prevention Resource Center, 2006). These attacks may be direct, such as hitting, threatening or intimidating others. They may also be indirect, such as spreading rumors or encouraging others to reject someone. Indirect bullying now includes the use of technology, such as emails, as a means of bullying. In a typical school day, however, bullying is thought of as the traditional form of physical bullying that often leads to violence.

Aggressive acts by, and on, students continue to plague schools. In 2003, public school students were more likely to report being bullied than private school students and rural 
students were more likely than urban and suburban students to report encountering bullying (National Center for Education Statistics, 2006). There is an inverse relationship between grade level and students' likelihood of being bullied; as grade level increased, likelihood of being bullied decreased. Sixth through twelfth grade students reported that younger students were more likely to fear for their safety at school; $14 \%$ of sixth graders, $7 \%$ of 9 th graders and $2 \%$ of 12th graders reported that they had been bullied at school (NCES, 2006).

In America's Children: Key Indicators of Well-Being 2003 (Federal Interagency Forum on Child and Family Statistics, 2005), it was stressed that "violence affects the quality of life of young people who experience, witness, or feel threatened by [violence]" (p.46). In addition to direct physical harm, "violence can also adversely affect victims' mental health and development and increase the likelihood that they themselves will commit acts of serious violence" (p. 46).

Recent studies have added a new dimension, expanding the research focus to include not only the aggressor (or bully) and the victim, but also the bystanders. School violence prevention programs have worked toward addressing the indicators of aggressive behavior and the subsequent reactions from victims and bystanders. Consequently, prevention efforts must focus on managing conflict, increasing effective communication, and building positive school climate. While prevention is constantly focused on maintaining a safe environment, research must continue to examine programmatic impact in order to determine what is working within each specific curriculum effort to deter violence.

\section{Participant Roles in Bullying Scenarios}

Research has identified specific roles of participants within the bully-victim-bystander dynamic, such as the reinforcer, outsider, and defender (Salmivalli, 1999; Twemlow \& Sacco 1996). The reinforcer encourages the bully, often "providing an audience...or inciting [the bully]" (p. 454). The outsider avoids contact with bully-victim conflicts, "[tending] to stay away and not take sides with anyone" (p. 454). Finally, the defender "takes sides with [the victim]", consoles the victim, and attempts to end a bully-victim conflict (p. 454).

Bystanders are at-risk for future victimization because of the role that they play with the victim as well as with the bully. Each respective role they fulfill in a bullying scenario can dramatically affect the subsequent aggressor-victim-bystander interaction. Bystander roles have also been identified within a more detailed structure (Twemlow \& Sacco, 1996). The victim-bystander and bully-bystander relationships define the two basic bystander characterizations. The victimbystander empathizes with the victim and "vicariously becomes victimized without physical participation." The bully-bystander relationship mirrors Salmivalli's reinforcer, as this individual encourages bullying by actively watching incidents and encouraging physical injury to the victim. Bully bystanders are recognized as those children eager to create diversions to deter or block adults from the altercation (Salmivalli, 1999; Smith, Twemlow, \& Hoover, 1999; Twemlow \& Sacco, 1996).

Other bystander roles reflect the nature of the bully-victim-bystander interaction. The sadistic bully-submissive victim-bully [bystander's] interests heighten with the bully's increased aggression. These interactions portray an active bystander amid aggressive behavior. This bystander hopes to take on an active role in encouraging the bully and simultaneously instilling fear in the victim. The bully-sadistic bully-submissive victim-victim-bystander or the bully bystander dynamic identifies the hierarchy of aggression and the voyeuristic nature of the bystander typically involved in this situation (Twemlow \& Sacco, 1996). In this scenario, conflict is initiated by the bully and subsequently affects the sadistic bully, who redirects aggression 
towards the submissive victim, the victim, and the bystanders (Twemlow \& Sacco, 1996). Due to the escalating factor in this scenario, bystanders have a more dynamic role than in less aggressive situations.

Bystanders typically associate more with either the victim or the bully, upsetting the power hierarchy within the school environment (Twemlow \& Sacco, 1996). The proactive victim-depressed bully--bully-bystander--victim bystander interaction simply initiates attention from peers and teachers for entertainment purposes (Twemlow \& Sacco, 1996). Individuals involved in this type of bullying typically are hoping to gain or maintain high social status among peers (Twemlow \& Sacco, 1996). Bystanders can engage in this scenario for their own personal or internal reward structure, including a heightened sense of belonging within the peer structure, gaining indirect gains in popularity or perceived acceptance by others at the cost of the victim.

Considering the potential bystander roles, Twemlow (2004) believes educators and school administration should provide "alternatives to bully, victim and bystander behavior, while encouraging self-reflection, helping and understanding others" (p. 16). Prevention programs to deter aggressive behavior are necessary to initiate change within school environments that experience prevalent aggression and victimization. Unfortunately, bystanders may be susceptible to fulfilling roles their peers designate as appropriate, often "[acting] in ways which are prone to maintain and encourage bullying rather than diminish it" (Salmivalli, 1999, p. 454). Consequently, bystanders "sometimes become self-fulfilling prophecies: the behavior of the individual starts to resemble more and more the expectations directed towards him" (Salmivalli, 1999, p. 455). Through their active or passive support that encourages bullying, bystanders "can share in the bully's status and power by becoming accomplices" (O'Connell, Pepler, \& Craig, 1999, p. 447). This behavior may hope to displace potential victimization by gratifying the aggressors' attempts to gain attention and maintain their social role as an aggressor.

\section{Research-based Prevention Program Evaluations}

Although much of the research literature on bullying has focused on understanding the roles in bullying scenarios, fewer studies have focused on the effects of prevention programs used as treatments for aggressive behaviors in order to avoid these scenarios. Several studies have been conducted, however, that provide a foundation for research-based prevention program evaluations. Programs aimed at modifying this aggressive behavior continue to build on prior research findings leading toward more specific outcomes to promote positive youth development. Some of the key findings of prevention program evaluations will allow researchers to consider future efforts that will potentially advance the field as a respected and integrated component of social and behavioral science.

Research from two Philadelphia elementary schools supported the need for "multiple [perspectives] from key participants in school contexts" (p. 78), specifically teachers, students, peers, in order to obtain an objective view of aggression and victimization (Hess \& Atkins, 1998). Given a teacher's daily interaction with students, the familiarity of one's peer group with individual behavior and personality and the importance of self-perception, researchers have begun to utilize these data collection sources as a means of identifying and analyzing the effects of aggressive behavior.

An evaluation of Peace Education Foundation's (PEF) conflict resolution and peer mediation program examined programmatic impact by examining changes within-school behavioral incident rates. The treatment school was compared to three non-treatment schools with similar enrollment trends, demographics and student behavioral incident rates associated with conflict 
(Barnett, Adler, Easton \& Howard, 2001). Results indicated that the PEF program affected school climate as evidenced by downward trends in incident referral rates for disobedience ( $40 \%$ decrease), disruptive behaviors and disrespectful language during the three years of program implementation. Incident rates at the non-treatment schools rose. Following program completion, formal reinforcement techniques were withdrawn from the school and one year later, incidents of disobedient behavior rose again at the treatment school. These trends indicate that student behavioral norms changed during program implementation to being more conducive to solving problems and minimizing conflict.

A similar research study suggested that teachers and program coordinators understand the prevalence of various subgroups of victims, and found that such distinctions are significant in evaluating the role of the bystander (Brockenbrough, Cornell, \& Loper, 2002). Other research has evaluated peer mediation programs (Cowie, 1998). These programs offer behavioral and emotional mediation, conflict resolution, mediation teams, counseling programs (one-on-one, group, and telephone help-line support) with peer staff and supervising adults. Researchers were "unanimously of the opinion that peer support schemes improved self-confidence, gave young people useful skills, enhanced their responsibility, and gave them a useful opportunity to take action against bullying in their schools" (Cowie, 1998, p.121). This intervention method encouraged students to openly communicate and helped students to positively view bullying incident reports to adults. Such efforts also increased feelings of their ability to create change and improve the overall school climate.

Best practices research has promoted the use of comprehensive, multilevel strategies that target bullies, victims, bystanders and communities. This may be accomplished through the use of school-level interventions designed to prevent or minimize bullying that will change the culture and school climate. They must include classroom-level interventions targeting teachers and other adults in school as well as student level interventions that target individual or small groups of victims and bullies (Dupper \& Whitted, 2005; Orpinas, Horne \& Staniszewski, 2003). Other research has examined programmatic effects by examining the effects of a teachertargeted psycho-educational program for bullying (Newman-Carlson \& Horne, 2004); student cognitive and affective perceptions of school safety (deLara, 2000), performance ratings of students on conflict resolution techniques, measurement of aggressive and pro-social behavior changes (Grossman, Neckerman, Koepsell, Liu, Asher, Beland, Frey \& Rivera, 1997), and teacher reports of externalizing behaviors post-program (Powell, Muir-McClain \& Halasyamani, 1995; Teglasi \& Rothman, 1999). One such example is the Aggressors, Victims and Bystanders program.

\section{Prevention Program: Aggressors, Victims and Bystanders}

Aggressors, Victims, and Bystanders: Thinking and Acting to Prevent Violence (AVB) is a violence prevention program designed for youth at risk (Slaby, Wilson-Brewer, \& Dash, 1994). Designed at Harvard's Educational Development Center, the overall goal of the AVB program is to decrease behaviors that may be considered dangerous to school staff, students and teachers. The purpose of AVB is to enable middle school students to gain the necessary skills they need in order to resolve conflicts, prevent violence, and ultimately change habits of thought.

While there is no single program that can address all of the risk factors associated with aggression and violence by youth, AVB is explicitly designed to target specific attitude and behavior modifying aspects of youth behavior. Over time, this may result in reducing violence, by youth against youth, particularly in middle schools. The premise of this program is that 
violence is a learned behavior and therefore can be unlearned. Similarly, conditions that promote violence can be changed, so that it is not learned in the first place (Slaby et al., 1994). AVB encourages students to examine the social roles of aggressors, victims, and bystanders within the school environment.

The program curriculum provides instruction in conflict management and encourages alternative thought processes in an effort to raise awareness about aggressive behavior and subsequently inhibit violence (Educational Development Center, 2004). AVB is unique when compared to other bullying prevention programs, in that it recognizes the bystander role and the ability of the bystander to either promote or discourage aggressive behavior. The AVB program theory is based on behavioral science research rooted in social learning theory (Bandura, 1977), which states that children learn primarily through imitating and observing adults (modeling). Individuals develop habits of thought regarding how to avoid, react and anticipate violence. Changing their habits of thought is necessary in order to avoid violence and to teach children most effectively how to handle acts of aggression.

By changing their habits of thought to effectively and proactively reduce violent outbreaks, bystander issues, and aggression levels, the AVB program strives to retrain youth to handle confrontation in new ways. Student interaction through the intervention process helps develop healthy characteristics in response to aggression and victimization. Like many prevention programs, AVB encourages student interaction in role-playing activities as a means of introducing and teaching these skills. This familiarizes students with effective methods of resisting aggression and victimization and promotes higher self-confidence for adolescents by practicing aggressor-victim-bystander situations within the various peer groups in their class.

\section{Methods}

This research was conducted in The School District of Palm Beach County (PBC), a large, mostly urban county with a diverse population of school-going adolescents. The district experienced a major school shooting in $\mathbf{2 0 0 0}$ when a student shot his favorite teacher on the last day of the school year. In response to this incident, the district school safety staff searched for a violence prevention program that would extend beyond the typical realm of aggression to include all parties potentially involved in violent incidents at schools. The extensive search culminated in selecting Aggressors, Victims and Bystanders (AVB) for implementation. Ultimately included were all Grade 6 classes as part of the district's overall effort to prevent other violent incidents from occurring. Although future violence prevention was the goal, the program was an intervention for current violent habits of thought and violent behaviors of students.

\section{Site Selection}

The PBC Safe Schools Center managed the program implementation and data collection in coordination with the PBC School Police. All sixth grade classes in the district in 2002-04 were eligible to participate and implement the AVB program, during social studies, health education and life skills courses. It was determined that all middle schools were to be included in the study over the three year program implementation. Two control group schools were randomly chosen prior to the study, and the remaining middle schools were randomly selected as treatment schools for implementation during one of the three-year intervention groups. All 1,040 sixth grade students would be included in the study by the third year.

The number of participant schools expanded during each of the three years for a total of 12 middle schools receiving the intervention and two middle schools functioning as control schools. 
Data collection occurred at the beginning of each school year as a pre-test and at the end of the school year as a post-test at all schools in the study. The program had a phased-in implementation plan for the three waves as follows: Year 1: 3 schools; Year 2: 4 schools, and Year 3: 5 schools in order to expand the program throughout the district.

\section{Sample and Participants}

At each school in the intervention group, all sixth grades classes were included in the study. During Year One (Y1), six classrooms in three middle schools implemented the prevention program and two schools served as assigned control groups, which remained constant for all three years. In Year Two (Y2), four classrooms in four additional middle schools implemented the program, and finally, seven classrooms in five middle schools implemented in Year Three (Y3). A total of seventeen classrooms in twelve treatment schools representing a wide geographic area and range of diverse populations participated in the study (pre-test $n=965$; post-test $n=916$ ). The two control groups were held constant (pre-test $n=168$; post-test $\mathrm{n}=161$ ) across all three years.

The total sample of 1,040 youth included: $51.1 \%$ White Non-Hispanic, $22.4 \%$ African American, $16 \%$ Hispanic, $0.5 \%$ Asian, 3.2\% other and 6.8\% unreported. There were 872 students in the intervention group and 168 in the control group. At the start of each school year, the 168 sixth graders that were in the original control group remained constant throughout the study. Control group retention rates were high; $161(95.8 \%)$ remained enrolled in the district for the threeyears and were used throughout the study. In the intervention groups, there were 270 participants in $\mathrm{Y} 1,232$ in $\mathrm{Y} 2$, and 370 in $\mathrm{Y} 3$. Intervention group retention rates were more vulnerable. Of the original 872 students taking the pre-tests, 775 completed the post-tests (78.6\%). The program was implemented in the treatment schools by a trained prevention program manager and school resource officers. Eleven school resource officers were trained in AVB program delivery and each were assigned several treatment schools and classrooms. The curriculum was delivered by the resource officers during regular class periods and replaced regularly scheduled teacher subject-based instruction.

All sixth grade middle school teachers participated in the study. A total of 20 classroom teachers (17 treatment group teachers, 3 control group teachers) were included to examine teacher perceptions of student habits of thought about violence prevention and attitudes and behaviors. Teachers observed the program implementation assessed behaviors for each of their treatment or control group students by completing a pre- and post-treatment survey about each student participant.

\section{Measures}

Students in all twelve schools completed two different surveys (Survey 1 and Survey 2) during pre, and post- program implementation. The surveys were designed to assess attitudes and beliefs related to self-efficacy, conflict resolution, and bystander strategies. Student Survey 1 items related to habits of thought about prevention of violence ("People's violent behavior can be prevented.") while Student Survey 2 focused on habits of thought about actual behaviors related to or in response to violence ("It's okay for you to fight other kids."). Students responded to nine items on Survey 1 concerning habits of thought about violence prevention and 24 items on Survey 2 related to habits of thought about violent behaviors. All items ranged from to (1) Don't Agree at All to (4) Completely Agree with 4 being the optimal score; negatively worded items were reverse coded for analysis. 
Teachers completed two self-administered instruments for all enrolled subjects during each of the three data collection years. Teachers recorded both control and intervention groups (pretest and post-test) for a total of two observations per student. The Teacher Survey was designed to assess their perception of student habits of thought about attitudes and behaviors related to violence in order to determine whether there was improvement after program implementation, and whether this improvement sustained over time.

\section{Procedure: Data Collection}

Teachers with treatment groups stayed in the classroom during the program delivery by school resource officers and observed the content as it was being delivered. All students were consequently rated by their teachers on 18 individual items by one of five ability levels ranging from 1-Always to 5-Never. Based on this five-point scale, a higher score indicates positive habits of thought and behaviors toward preventing violence.

Data collection occurred as each of the three surveys was administered pre- and post- to the prevention program. Table 1 summarizes the survey responses by survey type and year. Some attrition occurred over the course of the three years of collection due to students moving from the area or being absent the during data collection. Of the total population of sixth graders at the start of the study $(1,040), 965$ completed the pre-test $(92.8 \%)$ and 916 completed the post-test (88\%).

Table 1

Survey Responses by Type and Year

\begin{tabular}{|l|l|l|l|l|l|l|}
\hline & $\begin{array}{l}\text { Teacher } \\
\text { Survey } \\
\text { pre-test }\end{array}$ & $\begin{array}{l}\text { Teacher } \\
\text { Survey } \\
\text { post-test }\end{array}$ & $\begin{array}{l}\text { Student } \\
\text { Survey 1 } \\
\text { pre-test }\end{array}$ & $\begin{array}{l}\text { Student } \\
\text { Survey 1 } \\
\text { post-test }\end{array}$ & $\begin{array}{l}\text { Student } \\
\text { Survey 2 } \\
\text { pre-test }\end{array}$ & $\begin{array}{l}\text { Student } \\
\text { Survey 2 } \\
\text { post-test }\end{array}$ \\
\hline Year 1 T & 270 & 227 & 218 & 230 & 254 & 229 \\
\hline Year 2 T & 232 & 209 & 221 & 203 & 216 & 192 \\
\hline Year 3 T & 370 & 361 & 347 & 347 & 340 & 337 \\
\hline $\begin{array}{l}\text { Control } \\
\text { Year 1-3 }\end{array}$ & 168 & 161 & 163 & 158 & 155 & 158 \\
\hline $\mathbf{n =}$ & $\mathbf{1 , 0 4 0}$ & $\mathbf{9 5 8}$ & $\mathbf{9 4 9}$ & $\mathbf{9 3 8}$ & $\mathbf{9 6 5}$ & $\mathbf{9 1 6}$ \\
\hline
\end{tabular}




\section{Results}

The primary outcomes of interest were the change from baseline in:

(a) the student habits of thought related to violence prevention,

(b) student habits of thought related to attitudes about violence and physical behaviors related to violence; and

(c) teacher perceptions of student behaviors.

A series of bivariate and multivariate analyses were conducted to explore differences in Habits of Thought about Violence score. Scores were analyzed and compared across control/intervention group treatment and the pre-test/post-test status. To explore these effects, multivariate analysis was conducted using a series of three way ANOVA models.

The perceptions of teachers in regard to their student's habits of thought about violence were first explored. For this population, Teacher Habits of Thought scores among the control groups did not differ significantly from those in the intervention group $(p=.541)$. However, overall post-test scores were significantly higher than pretest scores $(p=.000)$. When compared in the three way analysis, scores did not differ significantly when comparing pre/post-tests scores for control and intervention groups (Table 2). 
Table 2

Comparison of Pre and Post-Test Scores on Habits of Thought about Violence Score for Teachers and Students

\begin{tabular}{|c|c|c|c|c|c|}
\hline & \multicolumn{2}{|c|}{ Control Group } & \multicolumn{2}{|c|}{ Intervention } & \multirow[b]{2}{*}{$\mathrm{F}$} \\
\hline & Pre-Test & Post-Test & Pre-Test & Post-Test & \\
\hline \multirow[t]{2}{*}{$\begin{array}{l}\text { Teacher Perceptions } \\
\text { of Student Habits of } \\
\text { Thoughts } \& \text { Behaviors } \\
\text { Related to Violence } \\
\text { (Note 1) }\end{array}$} & $n=168$ & $n=160$ & $n=831$ & $n=764$ & $0.37^{\mathrm{a}}$ \\
\hline & 4.24 & 4.33 & 4.19 & 4.31 & $8.59 * * \mathrm{~b}$ \\
\hline \multirow[t]{3}{*}{$\begin{array}{l}\text { Student Time } 1 \text { Habits } \\
\text { of Thoughts about } \\
\text { Violence (Note 2) }\end{array}$} & $n=163$ & $n=157$ & $n=786$ & $n=730$ & $14.60 * * * a$ \\
\hline & 2.94 & 2.81 & 2.94 & 3.11 & $16.62 * * * b$ \\
\hline & & & & & $16.90 * * * c$ \\
\hline \multirow[t]{3}{*}{$\begin{array}{l}\text { Student Time } 2 \text { Habits } \\
\text { of Thoughts about } \\
\text { Violence Behaviors } \\
\text { (Note 3) }\end{array}$} & $\mathrm{n}=161$ & $n=157$ & $\mathrm{n}=811$ & $\mathrm{n}=723$ & $20.18^{* * * a}$ \\
\hline & 3.05 & 3.38 & 3.01 & 3.19 & $116.87 * * * \mathrm{~b}$ \\
\hline & & & & & $9.82^{* * c}$ \\
\hline \multicolumn{6}{|c|}{ a indicates a comparison of control and intervention groups } \\
\hline \multicolumn{6}{|c|}{${ }^{\mathrm{b}}$ indicates a comparison of pretest and post test scores } \\
\hline \multicolumn{6}{|c|}{$\begin{array}{l}\text { " indicates a significant two way interaction between control group/intervention and pre- } \\
\text { test/post-test scores }\end{array}$} \\
\hline
\end{tabular}

Note 1: Teacher Habits of Thoughts Score was measured by the following items: Solves Problems with peers by behaving aggressively, Thinks before he/she acts (reverse coded), Has a short fuse when it comes to controlling his/her temper, Listens to what other have to say (reverse coded), Would respond aggressively to a dirty look by a peer, Seems to stay calm and level headed even if things don't go his/her way (reverse coded), Blows up at the slightest provocation, Respects other people's opinions and wishes (reverse coded), Tries to get what he/she wants from peers by acting aggressively, Just goes crazy when he/she gets mad, Insists on doing things his/her way, Is referred to by other students as a bully, Thinks he/she is always right, Would respond aggressively if another student accidentally tripped him/her, Exercises self control when angry or upset (reverse coded), Is more narrow minded when solving problems, Acts aggressively if he/she is not allowed to do what he/she wants, and Is willing to listen to reason in most situations (reverse coded). For these items, response options ranged from 1 - Always to 5- Never. These variables were combined into a composite mean score that served as a single dependent variable. This decision was based on a series of exploratory factor analysis models that consistently identified a one-factor solution. Cronbach's Alpha for this scale was .97.

Note 2: Student Survey 1 Habits of Thoughts score was measured by the following items: People's violent behavior can be prevented, There are certain things a person can do to help prevent violence, I myself can make a difference in helping to prevent violence, People can be taught to help prevent violence, Doing or saying certain kinds of things can work to help prevent violence, I can learn to do or say the kinds of things that help prevent violence, People can learn to become someone who helps others to avoid violence, Even people who are not involved in a fight can do 
things that help prevent violence, Even when I am not involved and it's not about me, and I can make a difference in helping to prevent violence. For these items, response options ranged from 1 - Don't Agree at All to 5-Completely Agree. These variables were combined into a composite mean score that served as a single dependent variable. This decision was based on a series of exploratory factor analysis models that consistently identified a one-factor solution. Cronbach's Alpha for this scale was .85.

Note 3: Student Survey 2 Violence Behaviors score was measured by the following items: It's okay for you to fight other kids (reverse coded), It's not okay for other kids to make fun of you, It's important to show other kids that you are ready to fight anyone who picks on you, When two kids are fighting each other, it's your problem, It doesn't involve you when one kids is picking on another, There are only two kinds of kids- the kid who fight and the kids who get beaten up, Sometimes you deserve to get pushed around by other kids, You feel like a champion when you fight some other kid, When two other kids are fighting each other, it's not right for you to join in, You get what you want from kids if you're a bully, You get respect when you boss other kids around, When two kids are fighting each other, it's okay for you to cheer for them, Sometimes you just need to yell and say mean things to other kids, When you yell and say mean things to other kids, it makes you feel bad about yourself (reverse coded), There are always other ways to solve an argument with some other kids besides hitting or getting hit (reverse coded), You don't get what you want from other kids by fighting with them (reverse coded), It makes you feel big and tough to be a bully, It's never okay to be a bully (reverse coded), You can make other kids do what you want by yelling at them, If you refuse to fight, other kids will think you're a loser, Sometimes you have only two choices - get punched or punch the other kid first, If other kids pick on you, you probably asked for it, When two other kids are fighting with each other, it's none of your business, and When two kids are fighting each other, it's alright for you to stand there and watch. For these items, response options ranged from 1 - Don't Agree at All to 5-Completely Agree. These variables were combined into a composite mean score that served as a single dependent variable. This decision was based on a series of exploratory factor analysis models that consistently identified a one-factor solution. Cronbach's Alpha for this scale was .80 .

In all three scales the data were factor analyzed using several models/rotations (principal axis factoring and least squares methods with a varimax, quartimax, and direct oblimin rotations). The criteria established in advance of the selection of factor items were: a factor loading of . 35 or higher; at least a .10 difference between the item's loading with its factors and each of the other factors; and interpretability (Kim \& Mueller, 1978). In all analyses, only one factor was identified which had an eigenvalue greater than 1.0. Additionally, review of the screen test plots indicated that a one factor solution was most appropriate.

With the student time 1 population, scores differed significantly both among treatment groups and among post/pre-tests. Respondents in the intervention treatment group had significantly higher scores $(X=3.01)$ than those in the control group $(X=2.87, p=.000)$. Overall post-test scores $(X=3.05)$ were significantly higher than pre-test scores $(X=2.93 ; p=.000)$. When compared in the three way analysis, post-tests scores were significantly higher for the intervention group $(X=3.11)$ than for the control group $(X=2.94, p=.000)$.

Alternately, the student time 2 population scores differed significantly among treatment groups and among post/pre-tests. Respondents in the control group had significantly higher scores $(X=3.21)$ than those in the intervention group $(X=3.10, p=.000)$. Overall post-test scores $(X=3.22)$ were significantly higher than pre-test scores $(X=3.01 ; p=.000)$. In the three way analysis, post-tests scores were significantly higher for the control group $(X=3.38)$ than for the intervention group $(X=3.19, \mathrm{p}=.000)$.

An overall comparison of pre-test and post-test intervention groups and control groups was conducted to examine whether there were significant differences for each of the groups on each individual survey (Table 3). This allowed for a more detailed examination of program impacts between two groups (control and intervention and pre- and post-). Teacher survey results indicate that there were significant differences between pre- and post-test scores when all three years are analyzed, however, there were no significant differences between control and intervention groups. 
Table 3

Overall Comparison of T-Test Analysis among Pre/Post-Test Groups and Control Intervention Treatments on Teachers and Student Scores

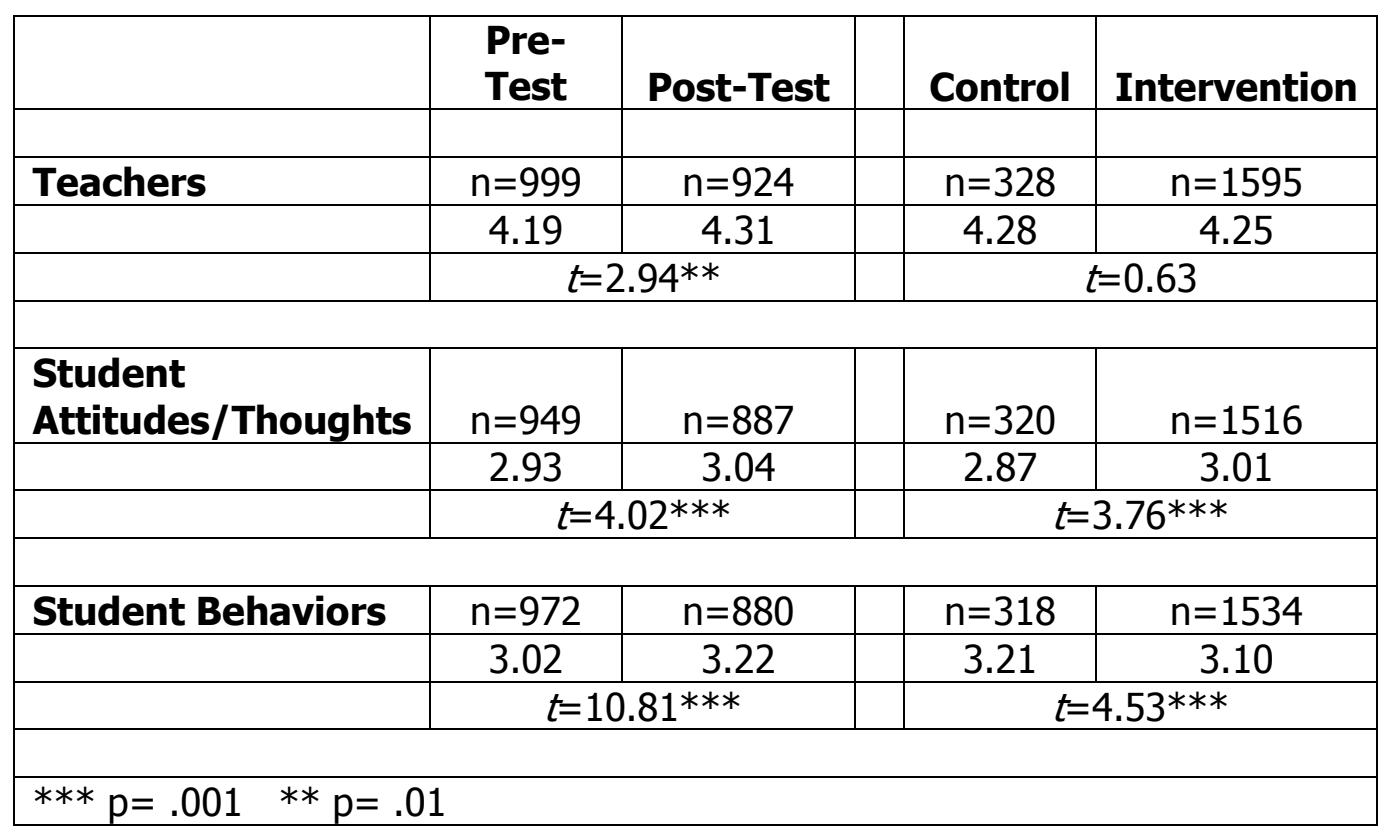

Student results indicate that for Survey 1 assessment of attitudes and thoughts, there were significant changes in the control and intervention groups as well as the overall pre- and posttest results, indicating positive changes in cognition related to violence and violence prevention.

Results for student assessment of habits of thoughts about behaviors (Student Survey 2) found that there was a significant difference post-test to pre-test scores, however, control groups had a higher score overall than intervention groups. Discussion and explanation for these and other findings will be conducted in the next section.

\section{Discussion and Conclusions}

The results of this randomized controlled study of Aggressors, Victims and Bystanders, a widely used violence prevention curriculum, provide some evidence of a positive effect. The three-way analysis allows for an exploration of overall effects in three dimensions. By focusing on teacher perceptions of student habits of thought related to violence, student habits of thought related to violence and student habits of thought related to violent behaviors, research outcomes were explored in specific programmatic areas. This will allow the impact of each program component to be assessed more directly toward the target of positive change in the school environment. It also allows for specific implications for field practitioners to be developed.

\section{Teacher Perceptions of Students Habits of Thought Related to Violence}

The primary outcomes of interest on the first dimension were the change from baseline in teacher perceptions of student habits of thought and behaviors related to violence. Although teacher scores did not differ significantly between control group and intervention group, this may be an indication that teachers had expectations for students that were high overall, no matter whether the students received the benefit of the curriculum. There are several possible explanations for these effects between control and intervention group teacher scores. Teachers 
stayed in the classroom during the content delivery by the school resource officers as a train the trainer approach, allowing them to actively observe and help to deliver the curriculum and internalize the content, therefore introducing an artifact of personal bias which may have somewhat elevated their perceptions of all students due to a "wishful thinking" factor. Given there was a major school shooting that resulted in a student charged with homicide of his "favorite" teacher in this district during the year prior to implementation, teachers had a vested interest in facilitating this program as a prevention and intervention measure.

Teacher t-scores for the student control group actually declined which may indicate that teachers perceived that those students who did not take the program did not experience any change in their habits of thought and behaviors about violence. In effect, they may have seemed to be in contrast even more so to those who did, resulting in a lower rating score. The treatment group, however, had overall post-test scores that were significantly higher than pretest scores, indicating that for those students who did receive the program, teachers had a heightened positive perception of these student's ability to think and act positively related to violence as a result. Changes in scores may be based primarily on teacher observations in the classroom, where aggressive behavior is less common than in other school settings such as the school grounds, hallways or cafeteria, where there is more interaction among students that could lead to violent thoughts and behaviors.

\section{Student Habits of Thought Related to Violence and Violence Behaviors}

The primary outcomes of interest on the second and third dimensions were assessed by the change from baseline in student habits of thought and behaviors related to violence. Results indicate that the intervention group did experience positive changes that resulted in significantly higher scores than the control group as well as post-test to pre-test. Student time 2 population scores indicate higher scores in behaviors among the control group and significantly higher post-test scores as well. There may be an effect of modeling behaviors that occurred as a result of the program. Once intervention student behaviors became more responsive positively to violent behaviors and playing different roles as aggressors, victims and bystanders, control group students may have also benefited from this as well. An overall more positive and safe environment would result as an added benefit of the program impacting individual responses and overall school culture related to violence prevention. Further, increasing the importance of the bystander role may have resulted in positive change for both the cognitive and physical habits of thought in students in both groups. Our findings reinforce the importance of using naturalistic observations of school children in behavioral studies to assess programmatic impact and detect detailed changes that occur.

\section{Limitations}

This study had several potential limitations. First, selection criteria may have resulted in limited assessment of control group changes as they were initially selected during the first year and then held constant. It may have been more realistic to assess control group changes yearly to determine whether there were any modeling behavior effects that resulted in significant changes. Second, the curriculum was evaluated after each wave of the study to provide point of impact information to the designers and to the school district. While this may have proven useful, it created time delays in assessing overall program impacts at the end of the three waves. Finally, there is the possibility of error in teacher observations of students. Because teachers were in the classroom during the training and had been affected by a significant violent event involving a fellow teacher, this may have caused program effects to be underestimated on some behaviors and overestimated on others as well as introduced the wishful thinking effect that may have influence control group scores over intervention group. 
We sought to minimize the potential for confounding by using a random three-year wave design and controlling students at two schools held constant.

\section{Recommendations}

This study was designed as an evaluation of the program under ideal conditions; differences may be smaller than might be seen if the curriculum is used as intended with whole-school implementation over several years. We conclude that this violence prevention program appears to lead to modest changes in student habits of thought about violence prevention and is leading to modest reductions in aggressive behavior and increases in positive pro-social behavior among sixth graders. The impact on this behavior outside of the school is unknown. These results indicate that the interventions may need to be continued and reinforced for the other years of middle school to further reduce aggressive behaviors over the longer term in individual schools.

\section{References}

Bandura, A. (1977). Social learning theory. Englewood Cliffs, NJ: Prentice-Hall.

Barnett, R.V., Adler, A., Easton, J., \& Howard, K.H. (2001). An evaluation of peace education foundation's conflict resolution and peer mediation program. School Business Affairs, volume, \# pp. 29-39.

Brockenbrough, K.K., Cornell, D.G., \& Loper, A.B. (2002). Aggressive attitudes among victims of violence at school. Education and Treatment of Children, 25, 273-287.

Cowie, H. (1998). Perspectives of teachers and pupils on the experience of peer support against bullying. Educational Research and Evaluation, 4, 108-125.

deLara, E. (2000). Adolescents' perceptions of safety at school and their solutions for enhancing safety and reducing school violence: A rural case study. Paper presented at the National Rural Education Association Conference, Charleston, SC, October 2000.

Dupper, D., \& Whitted, K. (2005). Best practices for preventing or reducing bullying in schools. Children in Schools, 27(3), 167-175.

Education Development Center. Special topic: Violence prevention. (2004). Teenage Health Teaching Module. Retrieved July 13, 2004, from http://www.thtm.org/special.htm\#description

Federal Interagency Forum on Child and Family Statistics. (2005). America's Children: Key National Indicators of Well-Being 2005. Retrieved May 10, 2006, from http://www.childstats.gov/americaschildren/index.asp

Fox, J.A., Elliot, D.S., Kerlikowske, R.G., Newman, S.A., \& Christeson, W. (2003). Bullying Prevention is Crime Prevention: A report by Fight Crime: Invest in Kids. Retrieved June 18, 2004, from http://www.fightcrime.org/reports/BullyingReport.pdf

Grossman, D.C., Neckerman, H.J., Koepsell, T.D., Liu, P.Y., Asher, K.N., Beland, K., et al. (1997). Effectiveness of a violence prevention curriculum among children in elementary school. Journal of American Medical Association, 277, 20, 1605-1611. 
Hess, L.E., \& Atkins, M.S. (1998). Victims and aggressors at school: Teacher, self, and peer perceptions of psychosocial functioning. Applied Developmental Science, 2, 75-89.

Hoover, J. H., Oliver, R., \& Hazler, R.J. (1992). Bullying: Perceptions of Adolescent victims in Midwestern USA. School Psychology International, 13, 15-16.

Nansel, T.R., Overpeck, M.D., Pilla, R.S., Ruan, W.J., Simons-Morton, B., \& Scheidt, P. (2001). Bullying behaviors among U.S. youth: Prevalence and association with psychosocial adjustment. Journal of the American Medical Association, 285, 2094-2100.

Nansel, T.R., Overpeck, M.D., Haynie, D.L., Ruan, J., \& Scheidt, P.C. (2003). Relationships between bullying and violence among U.S. youth. Archives of Pediatric and Adolescent Medicine, 157, 348-353.

National Center for Education Statistics. Indicators of School Crime and Safety: 2004. Indicator 6: Bullying at School. Captured May 10, 2006.

http://nces.ed.gov/pubs2005/crime safe04/indicator 06.asp

National Youth Violence Prevention Resource Center. Best Practices in Bullying Prevention and Intervention. Captured May 27, 2009.

http://www.stopbullyingnow.hrsa.gov/kids/tips-for-kids.aspx

Newman-Carlson, D. \& Horne, A. (2004). Bully busters: A psychoeducational intervention for reducing bullying behavior in middle school students. Journal of Counseling \& Development, 82, 259-267.

O'Connell, P., Pepler, D., \& Craig, W. (1999). Peer involvement in bullying: Insights and challenges for intervention. Journal of Adolescence, 22, 437-452.

Olweus, D. (1993). Bullying at school: What we know and what we can do. Oxford, UK: Blackwell.

Orpinas, P., Horne, A. \& Stanisewski, D. (2003). School bullying: Changing the problem by changing the school. School Psychology Review, 32(3), 431=434.

Powell, K.E., Muir-McClain, \& Halasyamani, L. (1995). A review of selected school-based conflict resolution and peer mediation projects. Journal of School Health, 65, 10, 426-431.

Salmivalli, C. (1999). Participant role approach to school bullying: Implications for interventions. Journal of Adolescence, 22, 453-459.

Slaby, R.G., Wilson-Brewer, R., \& Dash, K. (1994). Aggressors, Victims, and Bystanders: Thinking and Acting to Prevent Violence. Newton, Massachusetts: Education Development Center, Inc.

Smith, J., Twemlow, S.W., \& Hoover, D.W. (1999). Bullies, victims and bystanders: A method of in-school intervention and possible parent contributions. Child Psychiatry and human

Development, 30, 29-37. 
Teglasi, H., \& Rothman, L. (1999). A classroom-based program to reduce aggressive behavior. Journal of School Psychology, 39, 1, pp.71-94.

Twemlow, S. (2004). Preventing violence in schools. Psychiatric Times, 21. Retrieved May 25, 2004 from www.psychiatrictimes.com/p040461.html.

Twemlow, S.W., \& Sacco, F.C. (1996). A clinical and interactionist perspective on the bullyvictim-bystander relationship. Bulletin of the Menninger Clinic, 60, 296-314.

(C) Copyright of Journal of Youth Development Bridging Research and Practice. Content may not be copied or emailed to multiple sites or posted to a listserv without copyright holder's express written permission. However, users may print, download or email articles for individual use. 